\title{
ANÁLISE DO BALANÇO HÍDRICO CLIMATOLÓGICO DA SUB-BACIA HIDROGRÁFICA DO ALTO CAMAQUÃ-RS
}

\author{
ANALYSIS OF THE CLIMATOLOGICAL WATER BALANCE OF THE WATERSHED ALTO CAMAQUÃ
}

\section{RESUMO}

Este trabalho foi realizado na sub-bacia hidrográfica denominada Alto CamaquãRS, pertencente ao Bioma Pampa, uma região considerada estável e de alta importância para a conservação da biodiversidade. A principal atividade econômica e sociocultural da região é a pecuária familiar, sendo esta também fundamental para a manutenção do bioma em função da coexistência campo/gado. Foi realizado - Balanço Hídrico Climatológico (BHC) da sub-bacia para compreender seu comportamento nos meses de maiores déficits e excedentes hídricos, foram testados dois diferentes métodos de espacialização dos resultados: 1) Thorntwaite \& Mather (1955) e 2) BHCGeo (2013). A principal diferença entre os dois métodos está na determinação da CAD. O BHC foi calculado para três diferentes comportamentos de chuva: Ano Normal; Ano Seco; e Ano Chuvoso. Os métodos estudados demonstraram grande eficiência no cálculo do BHC. As diferenças entre as duas não modificam o comportamento geral da sub-bacia, não causando diferenças significativas nos déficit e excesso hídricos. Porém, o segundo método é mais eficiente para regiões com alta variabilidade de uso de solo. Além disso, o último apresentou resultados mais consistentes para situações que exigem análises mais detalhadas. Os resultados comprovam que os pecuaristas familiares somam prejuízos com muitos meses de déficit hídrico.

Palavras-chave: Déficit Hídrico, Pecuária Familiar, bioma Pampa.

\section{ABSTRACT}

This work was carried out in the sub-basin called Alto Camaquã, belonging to the Pampa Biome in a region considered stable and of high importance for the conservation of biodiversity. The main economic and socio-cultural activity of the region is family farming, which is also fundamental for the maintenance of the biome due to the coexistence of the field / livestock. In order to understand the behavior of the basin in relation to the months of major deficits and water surpluses, two different methods of spatialization of the results were tested. The main difference between the two methods lies in the determination of CAD. The $\mathrm{BHC}$ was calculated for three different rain behaviors: Normal Year; Dry Years; and Rainy Year. The methodologies studied demonstrated great efficiency in the calculation of BHC. The differences that occur in the both methods do not modify the general behavior of the basin and, therefore, do not cause significant differences in what concerns deficits and water excess. However, the second method is more efficient for regions with higher variability of the soil use. The results show that family ranchers suffer from many months of water deficit.

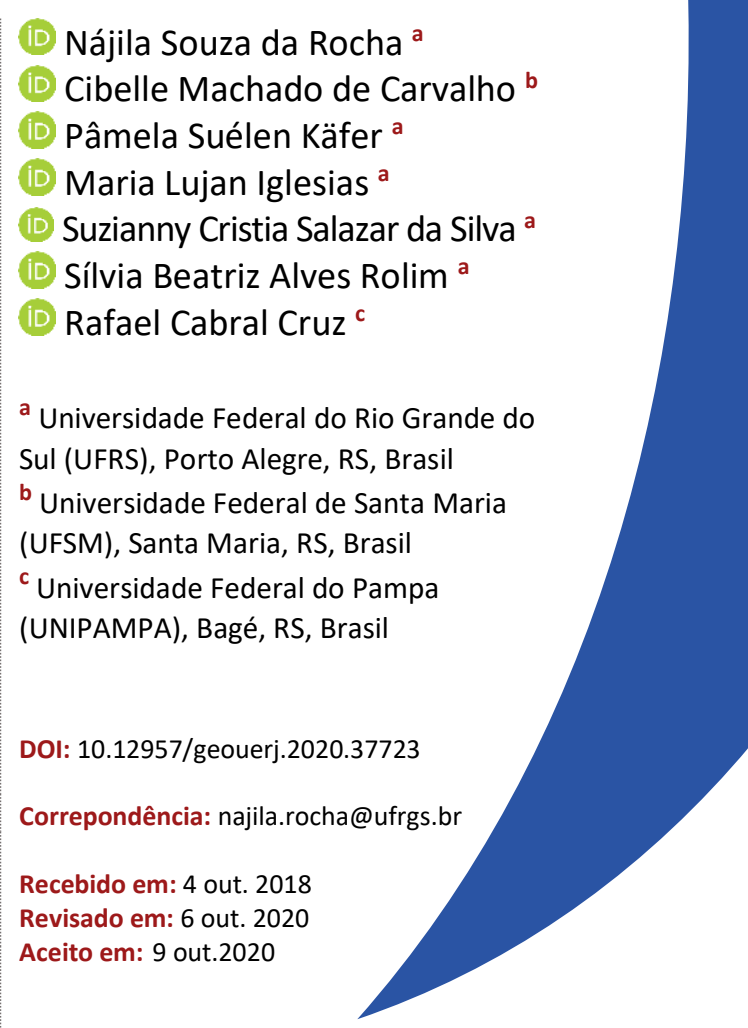
Keywords: Water deficit; family farming; Pampa biome. 


\section{INTRODUÇÃO}

Segundo dados hidrológicos, 97,5\% da água disponível na Terra são salgadas e 2,5\% estão concentrados em geleiras ou regiões subterrâneas de difícil acesso. Restam, portanto, 0,007\% de água doce para o uso humano, disponíveis em rios, lagos e na atmosfera (MACHADO, 2003). Desses, 12\% estão no Brasil, disponíveis para os diversos usos: irrigação, habitação, manutenção da vida silvestre, indústria e tecnologias. Segundo Lima et al. (1999), esses usos vêm aumentando a cada dia com a demanda de consumo pelo crescimento populacional.

Tal cenário exige aumento de tecnologia, produtos e serviços, resultando no aumento da demanda por recursos produtivos (máquinas, fábricas, terras agricultáveis, matérias-primas e água).

Em termos de ciclo hidrológico, e considerando que, globalmente, esse é um sistema fechado, a água seria infinita. O grande problema é a relação entre o tempo necessário para essa renovação, o ritmo de exploração dos recursos hídricos e o aumento acelerado da demanda. Contudo, a poluição dos sistemas, o desperdício da água potável, a falta de tecnologia empregada e o uso inadequado vêm preocupando especialistas dos meios acadêmico e político mundiais (TUNDISI, 2008; NASCIMENTO; HELLER, 2005; REBOUÇAS, 2003).

De acordo com dados da Organização das Nações Unidas para Alimentação e Agricultura (FAO, 2005 apud FAO, 2013), cerca de 1,8 bilhão de pessoas viverão em países ou regiões com escassez de água absoluta. Além disso, mais da metade da população mundial poderá viver sob estresse hídrico, o que corresponde a um desequilíbrio entre a oferta e a demanda de água em determinada região (FAO, 2013).

O Balanço Hídrico Climatológico (BHC) é uma das ferramentas mais usadas para a estimativa da deficiência e do excedente hídrico, da reposição e da retirada da água do solo e da quantidade de água armazenada no mesmo (CARVALHO NETO, 2011).

O BHC de Thorntwaite e Mather (1955) é estudado e difundido em todo o Mundo, pois considera que a disponibilidade de água no solo diminui à medida que o armazenamento é reduzido, estabelecendo o solo como um ingrediente ativo no seu cálculo (CARVALHO NETO, 2011).

Nessa abordagem, a Capacidade de Água Disponível (CAD) pelo solo em função do seu uso é levada em consideração, sendo parte fundamental do método proposto pelos autores supracitados. Outra variável determinante é a evapotranspiração (ETR), definida pelo conjunto de processos físicos (evaporação) e fisiológicos (transpiração) responsáveis pela transformação da água precipitada na superfície terrestre em vapor d'água (TUCCl; BELTRAME, 2000).

Este estudo foi realizado no território do Alto Camaquã-RS, uma sub-bacia da Bacia Hidrográfica do rio Camaquã, localizada no terço superior da mesma, abrangendo uma área de $8.172 \mathrm{~km}^{2}$ e compreendendo uma população de 24.700 habitantes (FEPAM, 2006). Bacia hidrográfica foi definida pela Política Nacional de Recursos Hídricos, instituída pela Lei Federal no 9.433/97 (BRASIL,1997), como unidade territorial de estudo e gestão, pois compreende-se que por suas características físicas, geográficas e ecológicas possui uma dinâmica 
estável, com fluxos energéticos estáveis. Além disso, numa bacia hidrográfica pode-se considerar o ciclo hidrológico na sua integridade (entradas e saídas de água), facilitando o ordenamento do território e o planejamento das ações de uso dos recursos naturais e ocupação do território (COLLISCHONN; TASSI, 2008).

O déficit hídrico e o excedente, calculados pelas diferentes metodologias de BHCs, são importantes para entender o comportamento de determinada bacia hidrográfica e o uso dos recursos naturais da mesma, sendo que meses com excedente de água poderiam significar uma fonte, a médio prazo, para os meses com déficit. Além disso, identificar os meses com déficit hídrico pode facilitar o planejamento dos cultivos anuais e, portanto, um melhor planejamento de todo o sistema produtivo.

Neste estudo objetivou-se caracterizar a bacia hidrográfica segundo o Balanço Hídrico Climatológico (BHC) e selecionar uma metodologia de BHC que melhor caracterizasse a área de estudo, levando em consideração seus diferentes usos e ocupações do solo e os valores da CAD.

\section{MATERIAL E MÉTODOS}

A série histórica de dados de precipitação utilizada foi de 1990 até 2013, excluindo anos com dados inconsistentes das 14 estações pluviométricas presentes na área de estudo (Figura 1).

Figura 1. Estações Pluviométricas da sub-bacia hidrográfica Alto Camaquã/RS.

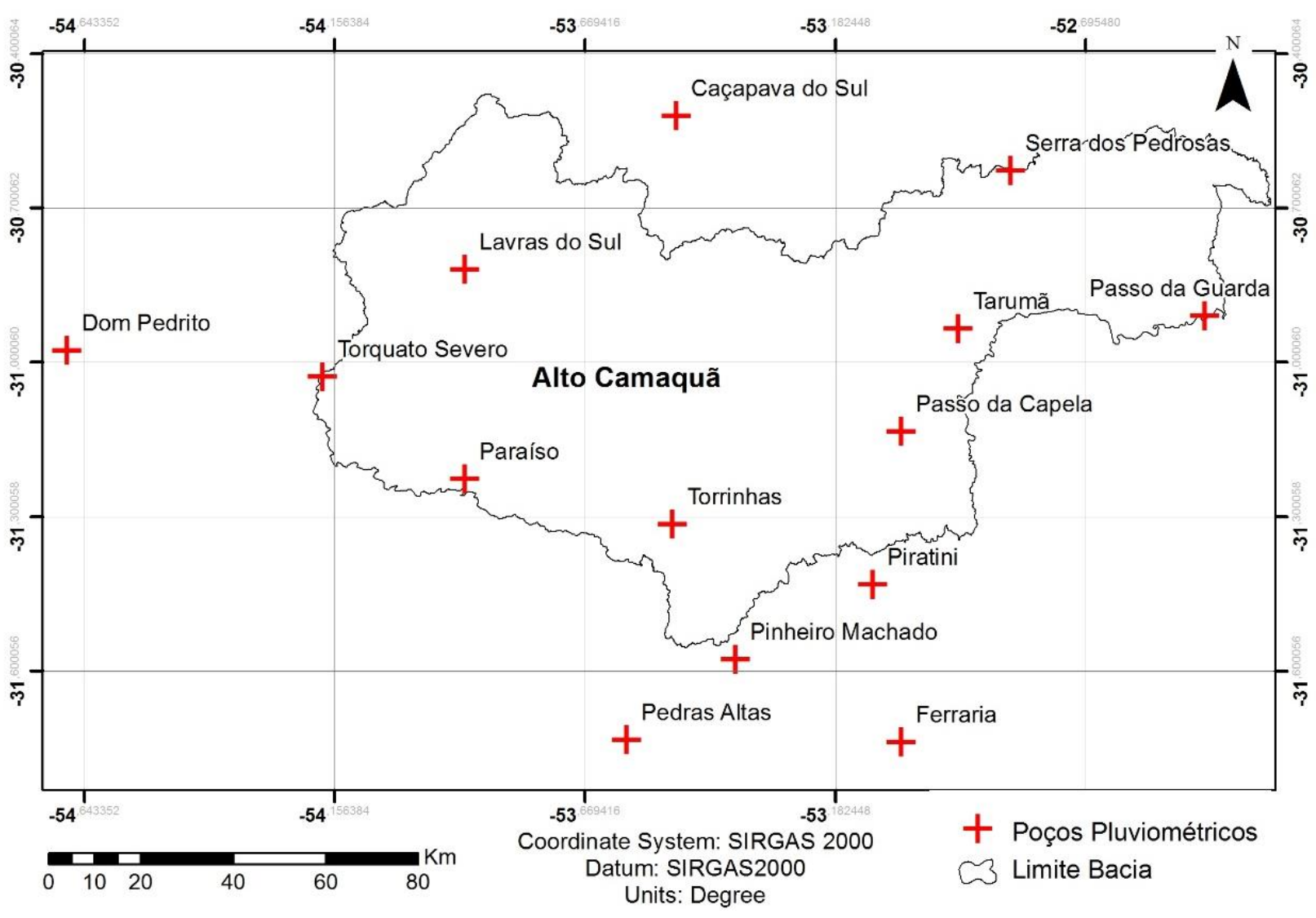

Fonte: Elaborado pelos autores através de dados da Agência Nacional das Águas (ANA). 
Primeiramente, foi realizada a média pluviométrica anual para os 23 anos estudados (Média Geral) para entender o comportamento das chuvas em cada ponto (Tabela 1). Em segundo lugar, foram selecionados três anos para cada ponto, denominados: Ano Normal; Ano Seco; e Ano Chuvoso.

Tabela 1. Estações pluviométricas utilizadas para o Balanço Hídrico Climatológico.

\begin{tabular}{llll}
\hline Ponto & Nome & Estação ANA & Média Geral $\mathbf{( m m})$ \\
\hline $\mathbf{1}$ & Piratini & 3153021 & 123,30 \\
$\mathbf{2}$ & Tarumã & 3052010 & 118,07 \\
$\mathbf{3}$ & Passo da Guarda & 3052007 & 107,85 \\
$\mathbf{4}$ & Serra dos Pedrosas & 3052012 & 130,69 \\
$\mathbf{5}$ & Lavras do Sul & 3053007 & 123,07 \\
$\mathbf{6}$ & Caçapava do Sul & 3053022 & 140,23 \\
$\mathbf{7}$ & Dom Pedrito & 3054002 & 118,17 \\
$\mathbf{8}$ & Torrinhas & 3153017 & 114,82 \\
$\mathbf{9}$ & Torquato Severo & 3154003 & 126,97 \\
$\mathbf{1 0}$ & Ferraria & 3153004 & 130,59 \\
$\mathbf{1 1}$ & Passo da Capela & 3153006 & 120,81 \\
$\mathbf{1 2}$ & Pedras Altas & 3153007 & 107,74 \\
$\mathbf{1 3}$ & Pinheiro Machado & 3153003 & 124,60 \\
$\mathbf{1 4}$ & Paraíso & 3153008 & 109,62 \\
\hline Fonte: Agência Nacional da Água (ANA) & &
\end{tabular}

Fonte: Agência Nacional da Água (ANA)

Em terceiro momento, foram elaborados três Balanços Hídricos Climatológicos diferentes para cada estação pluviométrica: Ano Normal (média pluviométrica mais próxima da Média Geral); Ano Seco (menor precipitação ao longo do ano/média anual muito abaixo da média geral); e Ano Chuvoso (maior precipitação ao longo do ano/média anual muito acima da média geral).

A ETP foi calculada a partir do método Thorntwaite e Mather (1955), um dos primeiros desenvolvidos exclusivamente para estimativa da evapotranspiração potencial mensal. Os dados de temperatura utilizados foram os fornecidos pelo Centro de Previsão de Tempo e Estudos Climáticos (CPTEC) e pelo Instituto Nacional de Meteorologia (INMET). Esses institutos fornecem as médias climatológicas calculadas a partir de uma série de dados de 30 anos observados.

A partir do uso e cobertura do solo, disponibilizados pelo Instituto Brasileiro de Geografia e Estatística, foram determinadas as Capacidade Máxima de Água Disponível (CAD) para cada pixel da sub-bacia de estudo (Figura 2). Esse termo representa o limite de água entre a capacidade de campo (CC) e o ponto de murcha permanente (PMP). A partir desses limites, pode-se determinar a capacidade de armazenamento de água disponível no solo, considerando a profundidade do sistema radicular (CARVALHO NETO, 2011). 
Figura 2. Capacidade Máxima de Água Disponível (CAD) para a sub-bacia hidrográfica Alto Camaquã-RS.

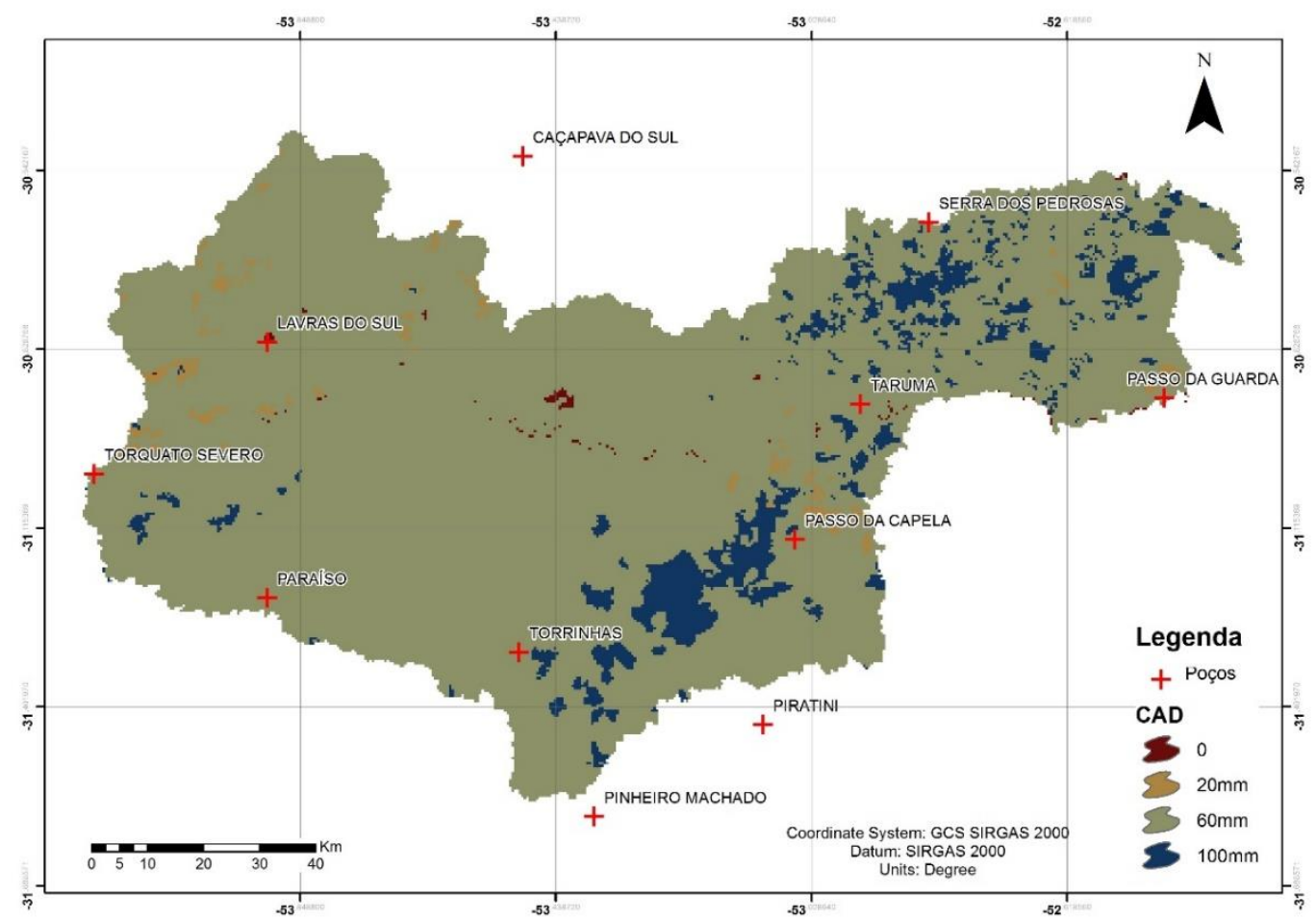

Fonte: Elaborado pelos autores.

A primeira metodologia utilizada consistiu no cálculo do BHC (THORNTHWAITE e MATHER, 1955). Os BHC mensais, calculados para os poços pluviométricos, foram georreferenciados e extrapolados para toda a bacia com a ferramenta IDW, que corresponde à interpolação entre cada ponto como uma influência local, diminuindo o peso à medida que a distância entre os pontos aumenta.

O segundo método utilizado no trabalho consistiu no cálculo do BHC através do BHCGeo (2013). Neste foi utilizado um script desenvolvido pelo Grupo de Pesquisa em Gestão de Recursos Hídricos (GERHI) da UFSM, em linguagem Python de programação (CARVALHO NETO, 2016). Foram utilizados 12 mapas de precipitação e 12 mapas de evapotranspiração (um para cada mês do ano), além de um mapa de CAD.

A principal diferença entre os dois métodos é que, no primeiro, é utilizado apenas uma CAD de $60 \mathrm{~mm}$ para toda a bacia hidrográfica, desconsiderando as diferenças de uso de solo. No segundo modelo, o BHC é calculado pixel a pixel pelo próprio script com discriminância para a CAD.

O mês de início do BHC deve ser aquele em que o solo está com a sua capacidade máxima atingida, após um longo período de chuvas frequentes. Foi selecionado o mês de agosto para início do BHC, levando em consideração os meses de maio a julho como período de maior frequência de chuvas na a região de estudo.

\section{RESULTADOS E DISCUSSÃO}

Para o Ano Normal, os meses que apresentaram déficit hídrico na maioria das estações foram: dezembro e janeiro (Tabela 2). Para este cenário o mês de janeiro não possuiu excedente hídrico em quaisquer estações. O máximo de déficit 
hídrico foi de -63,44mm e ocorreu no mês de dezembro no ponto 7 (Dom Pedrito). O máximo excedente foi de 214,6mm no mês de maio no ponto 12 (Pedras Altas).

Neste cenário, os meses de junho, julho, agosto e setembro, poderiam representar uma oportunidade de mitigação dos déficits hídricos para os meses de verão. A perda desses recursos pela sub-bacia significa uma oferta de água para as sub-bacias vizinhas do Médio e do Baixo Camaquã.

Tabela 2. Déficit e excedente hídrico calculado conforme Thorntwaite e Mather (1955), Ano Normal

\begin{tabular}{lllllllllllll}
\hline Ponto/Ano & Ago & Set & Out & Nov & Dez & Jan & Fev & Mar & Abr & Mai & Jun & Jul \\
\hline $1 / 2011$ & 66,2 & 86,1 & 63,6 & $-0,31$ & $-29,6$ & $-6,0$ & 14,6 & $-8,9$ & 10,9 & 51,5 & 76,5 & 73 \\
$2 / 1990$ & $-2,0$ & 104,6 & 86,6 & 132,3 & 13,5 & $-53,3$ & 17,0 & 131 & 20,0 & $-0,4$ & $-1,4$ & 38 \\
$3 / 2007$ & 153 & 32,8 & 31,8 & $-6,6$ & $-40,19$ & $-13,8$ & 0,00 & 4,20 & 39,8 & $-0,1$ & 178,8 & 74 \\
$4 / 2000$ & 30,2 & 185,0 & 79,4 & 37,2 & $-5,9$ & $-10,1$ & $-12,7$ & 53,6 & 18,7 & 106 & 126,6 & 78 \\
$5 / 2007$ & 133 & 106,1 & 71,0 & $-1,3$ & $-41,14$ & $-28,7$ & 0,00 & 43,1 & 15,3 & 13,4 & 244,1 & 60 \\
$6 / 1999$ & $-0,2$ & 75,9 & 89,6 & 18,12 & $-12,98$ & $-32,0$ & 0,00 & 0,00 & 146 & 104,9 & 117,3 & 116 \\
$7 / 2013$ & 31,16 & 125,7 & 132,5 & 132,55 & $-63,44$ & $-54,36$ & 0,00 & $-8,9$ & 6,98 & 124,0 & 28,05 & 21 \\
$8 / 2013$ & 64,47 & 71,07 & 125,8 & 133,09 & $-14,37$ & $-6,32$ & 35,6 & -24 & 0,00 & 52,83 & 42,48 & 28 \\
$9 / 1994$ & 29,16 & 39,60 & 104,5 & 1,45 & $-22,61$ & $-54,55$ & 87,6 & $-3,1$ & 60,5 & 58,23 & 62,95 & 229 \\
$10 / 1991$ & 87,41 & 57,79 & 176,1 & 164,69 & 15,16 & $-59,55$ & -61 & 0,00 & 122 & 36,25 & 73,46 & 96 \\
$11 / 1995$ & 9,41 & 92,59 & $-0,26$ & $-12,57$ & $-0,07$ & $-5,08$ & $-9,0$ & -30 & 0,00 & 0,00 & 86,01 & 414 \\
$12 / 2000$ & 41,69 & 60,41 & 19,28 & 10,26 & $-0,47$ & $-24,59$ & -14 & 9,08 & 12,4 & 214,6 & 92,18 & 117 \\
$13 / 1991$ & $-0,41$ & 21,25 & 169,1 & 85,79 & 32,57 & $-52,61$ & $-88,2$ & -44 & 257 & 53,48 & 98,48 & 72 \\
$14 / 1992$ & 37,07 & 63,77 & $-0,62$ & 1,17 & 8,94 & $-16,10$ & $-37,31$ & $-5,0$ & 303 & 141,7 & 194,2 & 117 \\
\hline
\end{tabular}

A estação de seca aumentou no Ano Seco e, como já esperado, houve mais meses com déficit hídrico de novembro a março na maioria dos pontos. Além disso, o máximo de déficit hídrico passou para -97,9mm, no mês de janeiro, e o máximo de excedente diminuiu para 160,9 no mês de setembro (Tabela 3).

Tabela 3. Déficit e excedente hídrico calculado conforme Thorntwaite e Mather (1955), Ano Seco.

\begin{tabular}{lllllllllllll}
\hline Ponto/Ano & Ago & Set & Out & Nov & Dez & Jan & Fev & Mar & Abr & Mai & Jun & Jul \\
\hline $1 / 1999$ & 2,81 & 62,79 & 62,09 & $-22,4$ & $-36,0$ & $-68,6$ & $-26,9$ & $-15,0$ & 0,00 & 0,00 & 62,44 & 59,55 \\
$2 / 2010$ & 32,21 & 87,59 & $-16,4$ & $-27,6$ & $-29,9$ & 0,00 & 0,00 & $-36,6$ & 0,00 & 40,91 & 131,3 & 57,05 \\
$3 / 1996$ & 96,12 & 8,73 & 22,58 & $-1,24$ & $-29,5$ & 115,0 & $-20,9$ & $-10,2$ & 0,00 & $-31,2$ & 17,51 & $-5,21$ \\
$4 / 1991$ & 3,42 & 17,03 & $-8,67$ & $-3,59$ & 24,27 & $-55,9$ & $-31,2$ & $-26,9$ & 127,1 & 31,06 & 72,81 & 98,64 \\
$5 / 2010$ & $-0,22$ & 94,81 & $-16,7$ & $-41,1$ & $-69,6$ & 0,00 & 3,07 & $-41,9$ & $-5,41$ & 0,74 & 44,49 & 193,9 \\
$6 / 2013$ & 100,7 & 17,32 & 91,76 & 102,6 & $-39,8$ & $-50,4$ & -26 & 0,00 & 51,00 & 89,01 & 33,28 & 18,34 \\
$7 / 1999$ & $-1,30$ & 34,56 & 92,21 & $-35,4$ & $-72,0$ & $-94,0$ & $-28,5$ & 0,00 & 45,93 & 37,33 & 68,75 & 28,43 \\
$8 / 1999$ & 0,17 & 62,67 & 48,46 & $-14,8$ & $-50,2$ & $-97,9$ & $-32,9$ & 0,00 & 8,88 & 27,68 & 91,98 & 74,77 \\
$9 / 2011$ & 21,26 & 20,80 & 114,1 & $-31,6$ & $-74,3$ & $-83,3$ & 0,00 & $-63,0$ & $-6,95$ & 0,00 & 33,00 & 88,03 \\
$10 / 2005$ & $-0,14$ & 39,35 & $-0,69$ & 66,16 & 3,66 & $-33,7$ & $-47,6$ & $-4,73$ & 118,9 & 122,6 & $-3,50$ & 28,71 \\
$11 / 2005$ & 37,61 & 160,9 & 96,09 & $-31,7$ & $-71,5$ & $-70,9$ & $-20,1$ & $-44,2$ & 34,90 & 104,2 & $-0,09$ & 30,79 \\
$12 / 1999$ & 24,99 & 47,91 & 43,48 & $-0,55$ & $-35,6$ & $-41,9$ & $-62,6$ & $-47,1$ & 48,75 & 12,34 & 119,8 & 81,02 \\
$13 / 2005$ & 56,17 & 174,3 & 65,86 & $-37,6$ & $-54,3$ & $-68,5$ & $-44,8$ & $-34,1$ & 0,00 & 58,62 & 23,58 & 29,77 \\
$14 / 1999$ & 3,67 & 43,27 & 66,96 & $-9,30$ & $-23,8$ & $-76,7$ & $-25,4$ & $-4,61$ & 0,00 & 11,04 & 85,68 & 40,17 \\
\hline
\end{tabular}


Neste cenário, os meses de junho a setembro, também, são meses de produção de água, porém, em quantidades muito menores que no ano normal. Apesar disso, algumas das estações apresentaram déficit hídrico nesse período.

O Ano Chuvoso possui a maioria dos pontos com déficit hídrico nos meses de janeiro e fevereiro, com valores superiores aos observados nos demais cenários. Neste, observou-se que o menor déficit hídrico ocorre em fevereiro no ponto 9 (Torquato Severo) no valor de $-38,2 \mathrm{~mm}$. Observa-se que houve um aumento de $40 \%$ no menor déficit hídrico em relação ao Ano Normal e um aumento em torno de 60\% no máximo excedente hídrico (336,4mm) que, neste cenário, ocorre em setembro no ponto 3, Passo da Guarda (Tabela 4).

Tabela 4. Déficit e Excedente Hídrico calculado conforme Thorntwaite e Mather (1955), Ano Chuvoso

\begin{tabular}{lllllllllllll}
\hline Ponto/Ano & Ago & Set & Out & Nov & Dez & Jan & Fev & Mar & Abr & Mai & Jun & Jul \\
\hline $1 / 2002$ & 196, & 160,6 & 160,7 & 48,89 & 282,2 & $-18,3$ & 1,45 & 284,1 & 251,0 & 128,4 & 125,4 & 92,549 \\
$2 / 2002$ & 81,4 & 152,2 & 163,1 & 57,79 & 314,6 & $-1,26$ & $-15,0$ & 91,77 & 192,2 & 125,0 & 181,5 & 125,54 \\
$3 / 2002$ & 98,4 & 60,73 & 145,2 & 71,00 & 308,7 & $-1,36$ & $-30,8$ & 79,15 & 122,5 & 108,6 & 130,2 & 185,53 \\
$4 / 2002$ & 204 & 166,2 & 265,9 & 214,8 & 117,4 & 42,1 & $-10,1$ & 83,21 & 145,0 & 130,5 & 210,8 & 191,43 \\
$5 / 2001$ & $-0,5$ & 336,4 & 30,95 & 39,50 & $-7,20$ & 58,8 & $-0,01$ & 70,59 & 291,7 & 32,62 & 195,9 & 85,376 \\
$6 / 1997$ & 74,9 & 13,92 & 266,2 & 155,5 & 239,2 & $-24,3$ & 194,3 & $-4,06$ & 0,90 & 95,31 & 163,6 & 107,64 \\
$7 / 2003$ & 81,0 & 1,40 & 74,81 & 126,5 & 81,55 & $-29,5$ & 108,6 & 90,44 & 126,7 & 160,4 & 144,9 & 27,131 \\
$8 / 2002$ & 240 & 269,6 & 182,8 & 82,39 & 311,8 & 33,7 & $-9,65$ & 241,9 & 246,4 & 97,28 & 105,2 & 110,37 \\
$9 / 2002$ & 194 & 163,5 & 156,2 & 98,95 & 192,5 & 25,2 & $-38,2$ & 154,3 & 232,9 & 88,83 & 149,9 & 141,83 \\
$10 / 2002$ & 196 & 156,6 & 182,4 & 72,09 & 293,8 & 58,0 & $-8,00$ & 171,7 & 213,1 & 125,7 & 146,5 & 85,149 \\
$11 / 2002$ & 196 & 98,8 & 164 & 80,59 & 295,9 & $-4,54$ & $-6,44$ & 84,87 & 215,1 & 161,2 & 143,5 & 124,75 \\
$12 / 2002$ & 209 & 135,0 & 151,2 & 44,26 & 174,4 & $-1,48$ & $-11,9$ & 156,3 & 253,5 & 35,54 & 152,0 & 138,12 \\
$13 / 2002$ & 197 & 192,1 & 160,8 & 80,59 & 260,2 & $-5,50$ & 4,87 & 323,4 & 277,6 & 97,28 & 176,3 & 86,874 \\
$14 / 2001$ & $-0,1$ & 420,7 & 120,3 & 61,89 & $-5,86$ & 0,00 & $-18,3$ & 108,8 & 191,5 & 29,38 & 222,2 & 130,47 \\
\hline
\end{tabular}

Os resultados apresentados demonstram um alto déficit hídrico para a bacia do Alto Camaquã, principalmente, nos meses de janeiro e fevereiro nos cenários de Ano Normal e Ano Seco. Porém, nos meses de dezembro a março, algumas estações apresentaram déficit hídrico, mesmo no Ano Chuvoso.

O excedente hídrico gerado nos meses invernais, de junho a setembro, para todos os anos de estudo, na maioria das estações, demonstra a existência de produção de água no Alto Camaquã e que esta deveria ser melhor gerida e manejada, conforme as necessidades dos pecuaristas familiares.

Além disso, o BHC foi calculado com valor de CAD $60 \mathrm{~mm}$, que representa a maior parte da bacia, caracterizada por uma vegetação campestre. Uma possível mudança no uso e ocupação do solo para atividades do agronegócio causaria uma diminuição deste valor e um aumento do déficit hídrico.

Ao espacializar o BHC, pode-se observar o comportamento da bacia em todo o seu território. Na Figura 3 é apresentado o mês de fevereiro para os três cenários, nos dois métodos executados, demonstrando a existência de déficit hídrico, inclusive no Ano Chuvoso. 
Figura 3. Déficit e Excedente Hídrico do Alto Camaquã para o mês fevereiro.
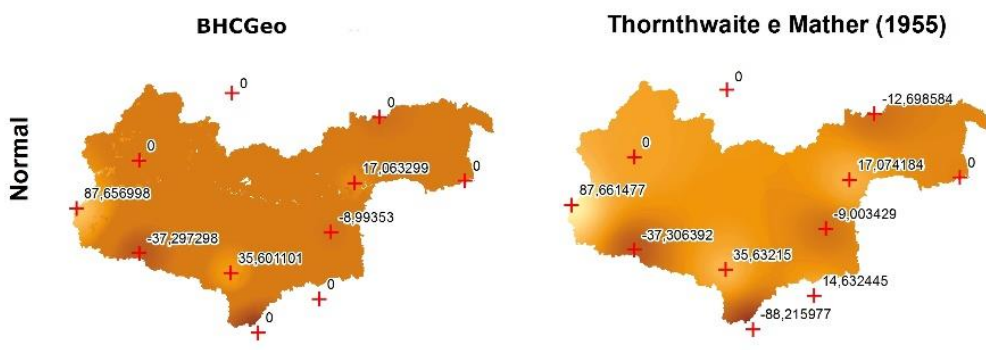

\section{Balanço Hídrico Climatológico -Fevereiro -}
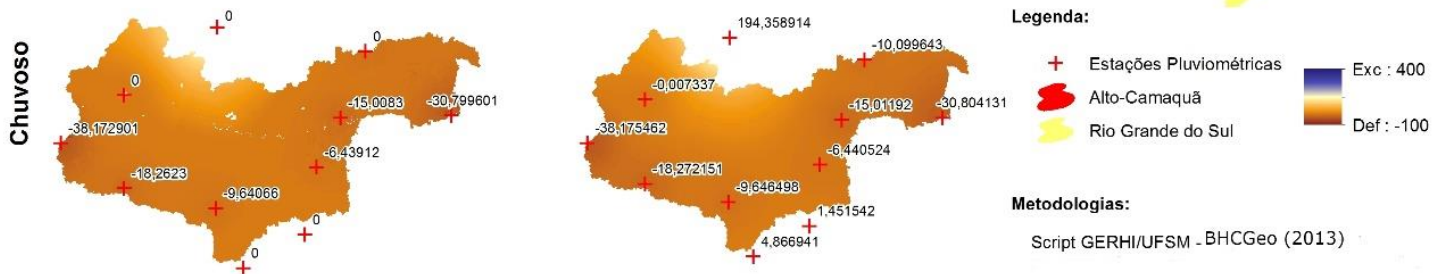

Script GERHIJUSM - BHCGeo (2013)
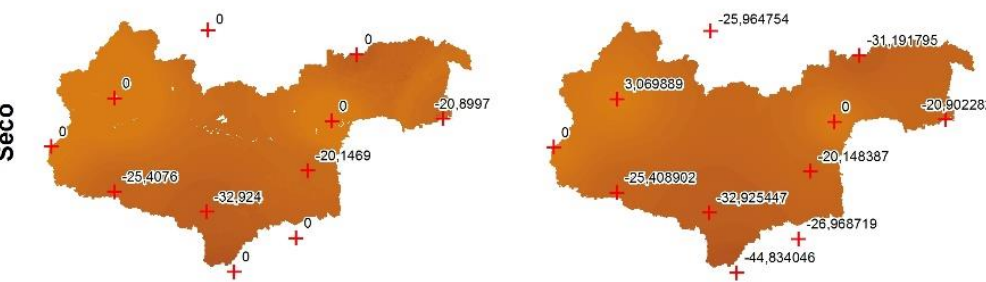

Thorntwaite e Matter (1955) para CAD - 60mm

Fonte:

$$
\begin{aligned}
& \text { Precipitação - ANA (Hidroweb) } \\
& \text { Temperatura - CPTEC e INPE }
\end{aligned}
$$
CAD - Carvalho Neto (2011)

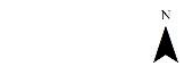

Sistema de Coordenadas: GCS SIRGAS 2000 $\begin{array}{llll}0.525 & 50 & 75 & 100\end{array}$ \begin{tabular}{llll}
12,525 & 50 & 75 & 100 \\
\hline
\end{tabular}

Tapia e Novelo (2016) explicam que, em consequência dos usos e ocupações do solo e da exploração indiscriminada dos recursos naturais, em qualquer cenário de balanço hídrico para bacias hidrográficas de alta exploração, continuaria existindo uma incongruência entre a demanda e a disponibilidade dos recursos hídricos. Os autores ainda ressaltam que este déficit implica na necessidade de obtenção de novas fontes hídricas em médio prazo ou de reorganização dos usos das fontes existentes.

Segundo estudo realizado na região dos Pampas da Argentina (CAMPO et al. 2016), as precipitações são fatores de impacto desde a época do povoamento do território e mais importantes para o desenvolvimento de seus habitantes e suas atividades produtivas. Segundo os mesmos autores, nos últimos anos, o território do Bioma Pampa vem sofrendo variabilidades meteorológicas que passam por longos períodos de seca até as mais severas inundações.

Desta maneira, observa-se um desdobramento importante deste trabalho no que se refere ao preparo das populações dos vales do Alto Camaquã para enfrentamento de eventos extremos, principalmente nos anos mais chuvosos e nos meses de abril a julho com maiores precipitações médias (Figura 4).

Além disso, os modelos do IPCC (2014) para esta região indicam que os meses de inverno receberão chuvas mais intensas e mais concentradas, aumentando os excedentes hídricos e o escoamento superficial da bacia até o final do Século XXI. O Alto Camaquã é, portanto, um produtor de água para as sub-bacias do Médio e do Baixo Camaquã, nos meses de inverno, principalmente nos anos mais chuvosos. Em estudo realizado por Rocha et al. 
(2019) os autores discutiram a vulnerabilidade dos pecuaristas familiares frente ao déficit hídrico e concluíram que o território do Alto Camaquã é frágil aos impactos ambientais causados pela falta de água. Além disso, os autores ressaltam que os efeitos dessa fragilidade poderão ser cumulativos e sinérgicos quando levadas em consideração as previsões dos modelos de mudança climática previstos pelo IPCC, de alongamento das estações de seca.

Esses resultados demonstram que há uma necessidade urgente de previsão de novas formas de uso dos recursos naturais e de implantação de nova política hídrica, que consiga atender as demandas das populações mais vulneráveis, já que estas cumprem um papel importante na manutenção de ecossistemas naturais, como é o caso dos pecuaristas familiares do Alto Camaquã.

Ademais, a presença dos pecuaristas familiares pode ser considerada fator determinante para a produção de água nos meses invernais, pois são eles que preservam os campos nativos do bioma (melhorando a infiltração das águas da chuva) e, consequentemente, o balanço hídrico do território. Uma mudança de cultura, como a inserção de monoculturas de Eucalipto, por exemplo, significaria também uma mudança no comportamento hídrico na bacia e a diminuição desta produção. Rocha et al., (2020) analisaram o aumento dos cultivos florestais no bioma Pampa desde 2006 com a chegada das multinacionais florestais e concluíram que além das alterações paisagísticas dos recursos naturais da região, não há possibilidade de os benefícios econômicos serem invertidos por um aumento do número de empregos de qualidade, e mesmo dos benefícios de melhorias infra-estruturais.

Sendo assim, os impactos gerados pela falta de gestão dos recursos hídricos com o objetivo de manter essas famílias na região, seriam sofridos também pelo Médio e Baixo Camaquã.

Figura 4. Déficit e Excedente Hídrico do Alto Camaquã para o mês julho.
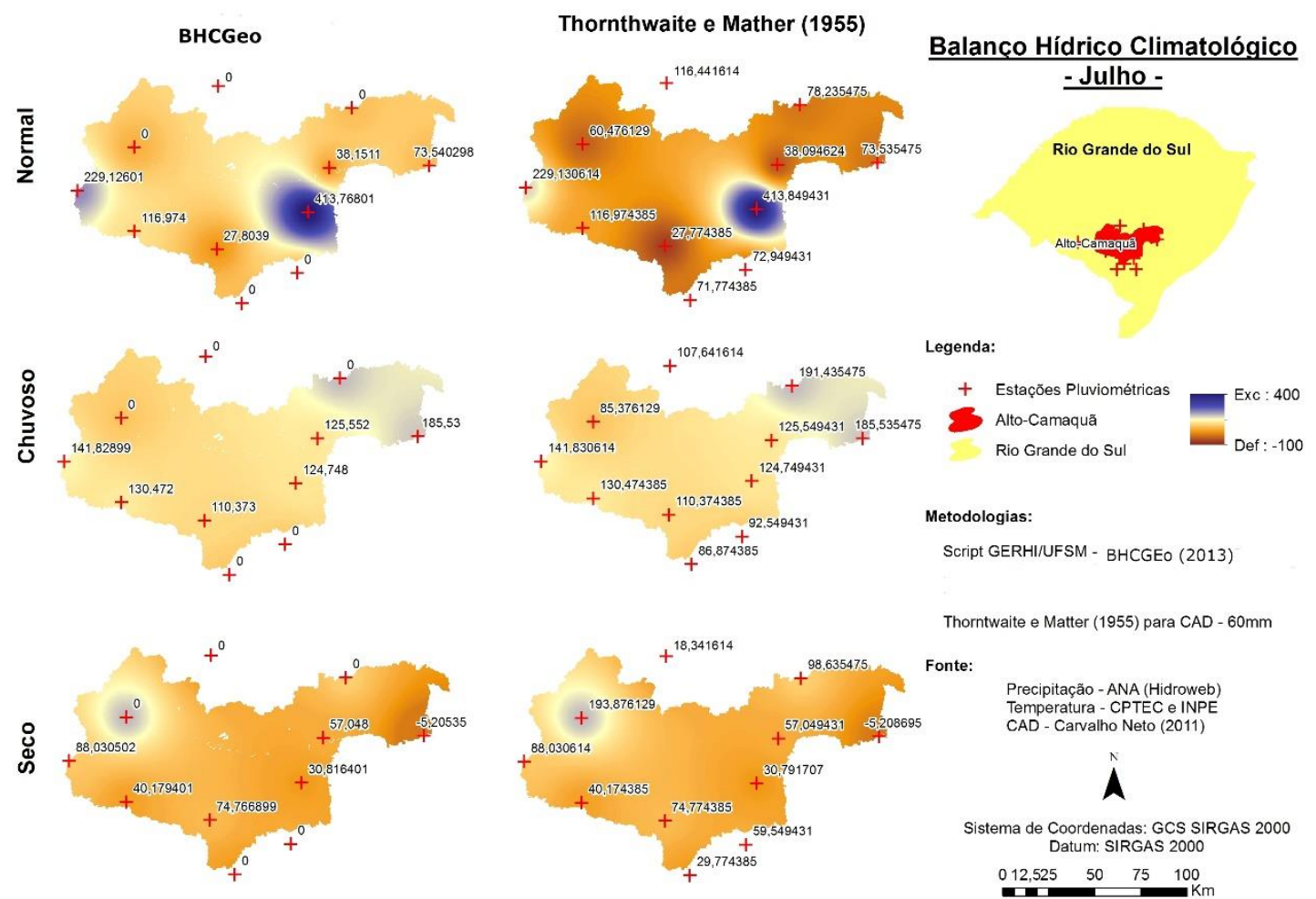
Apesar de os métodos se comportarem de maneira muito semelhante, o BHCGeo não considera pontos fora da bacia que influenciam na mesma e modificam os resultados. Na sub-bacia de estudo, em que a CAD é basicamente a mesma em todo o território, há pouca variação de um método de espacialização para outro (Figura 5), em áreas com maior variabilidade do território as diferenças entre os métodos seriam maiores.

Figura 5. Déficit e Excedente Hídrico do Alto Camaquã para o mês abril

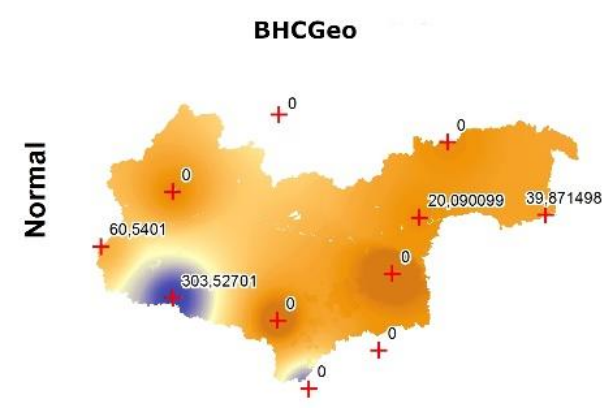

Thornthwaite e Mather (1955)
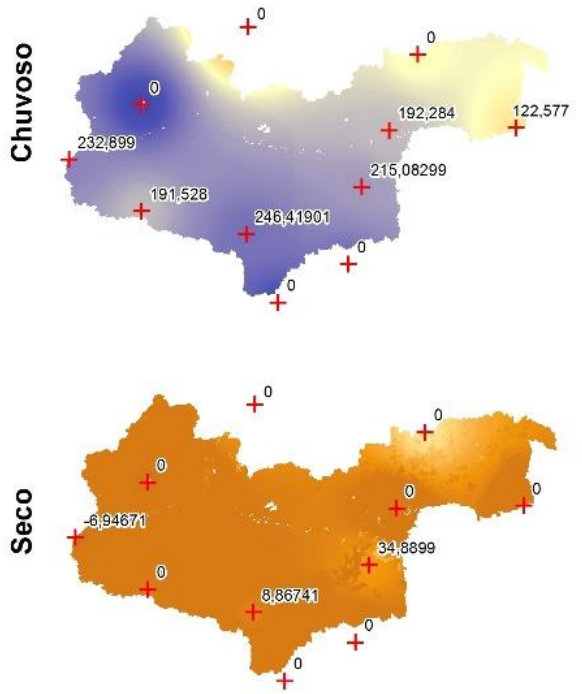

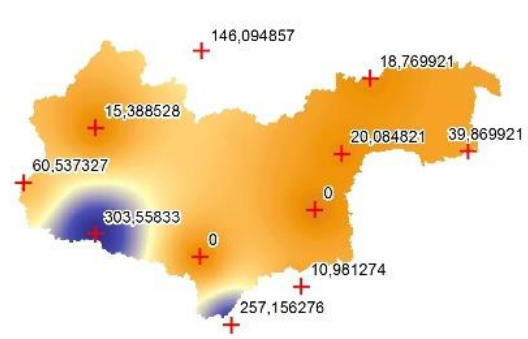

Balanço Hídrico Climatológico -Abril -

Rio Grande do Sul

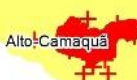

Legenda:

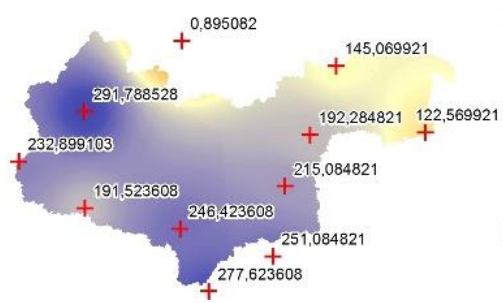

+ Estaçōes Pluviométricas

+ Estaçōes Pluviom Rio Grande do Su Exc : 400
Def : -100

Metodologias:

Script GERHI/UFSM - BHCGeo (2013)

Thorntwaite e Matter (1955) para CAD - 60mm

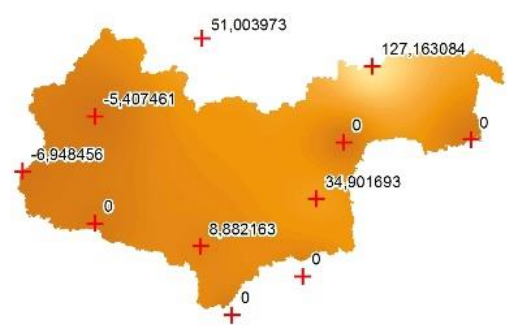
Fonte:
Precipitação - ANA (Hidroweb) Temperatura - CPTEC e INPE

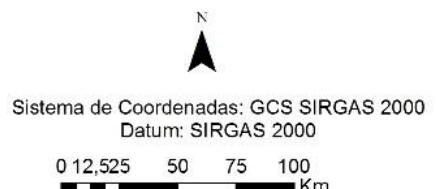
CAD - Carvalho Neto (2011)

A única diferença observada, quando se trata de déficit hídrico, foi para o mês de agosto para a estação de Torrinhas no Ano Normal (Figura 6). No entanto, isso só ocorreu porque o BHCGeo considera sempre que no primeiro mês do BHC não há alteração no armazenamento de água no solo o que, segundo Pereira et al. (2007), é o mais correto, pois, teoricamente, o solo deve estar em sua capacidade máxima de água disponível (CAD) no primeiro mês do balanço.

A principal característica do modelo do BHCGeo é mesmo a discriminância pixel a pixel em função do valor de CAD. O ponto Lavras do Sul cai exatamente em um valor de CAD igual a zero, pois é uma área urbana e, portanto, nota-se uma diferença de valores do BHC para todos os anos de análise.

Em uma bacia hidrográfica com alta variabilidade no uso e ocupação do solo, poderiam ocorrer diferenças mais significativas entre os métodos. 
Figura 6. Déficit e Excedente Hídrico do Alto Camaquã para o mês Agosto.
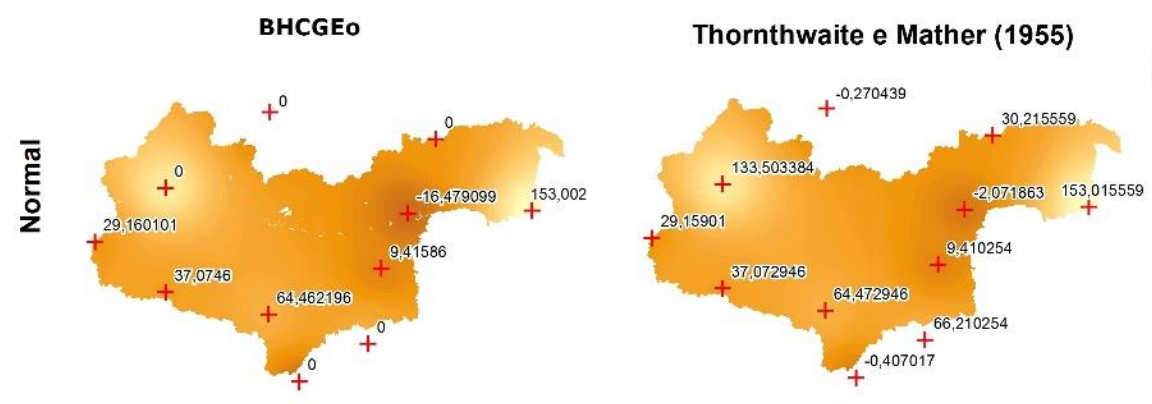

\section{Balanço Hídrico Climatológico -Agosto -}
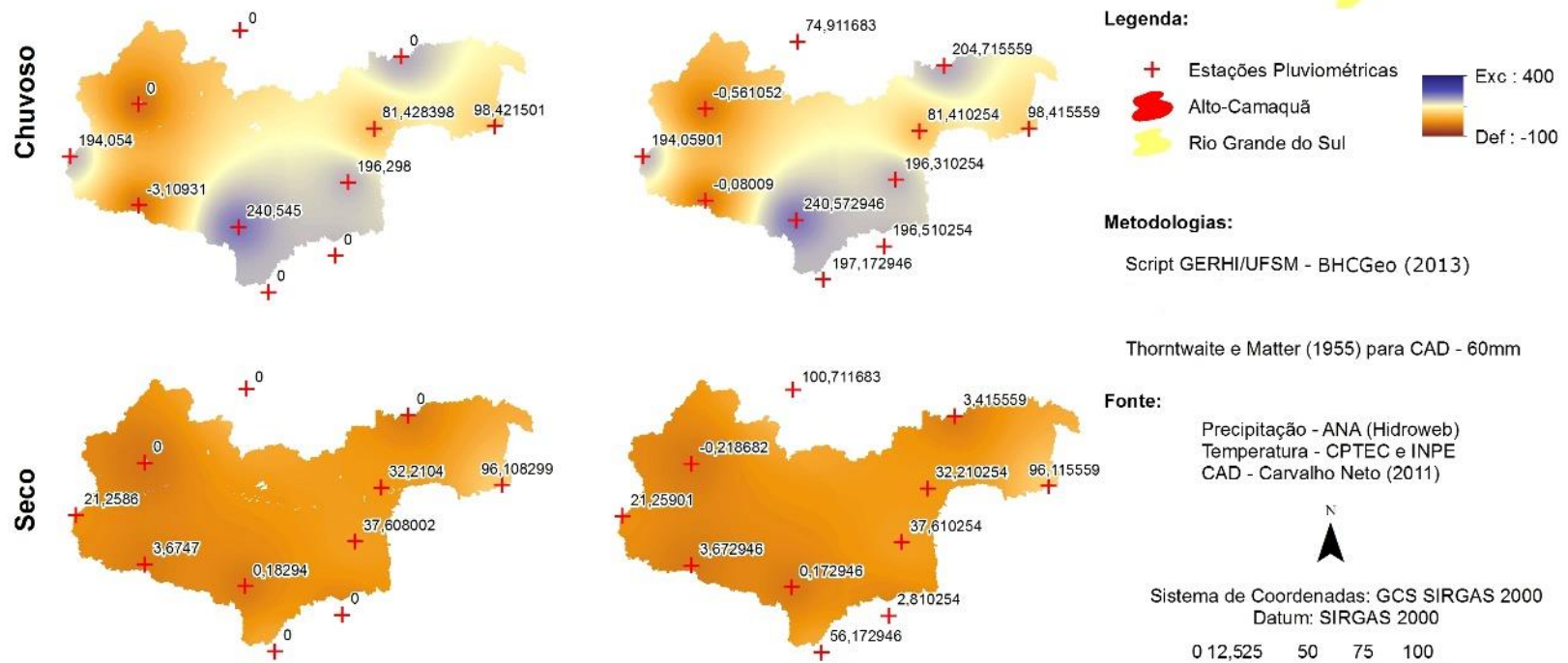

Thorntwaite e Matter (1955) para CAD - 60mm Fonte: Precipitação - ANA (Hidroweb) CAD - Cavalho Neto (2011)

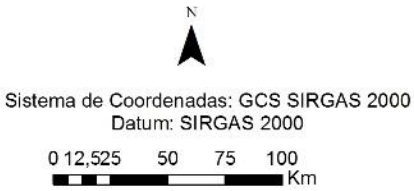

Ademais, mesmo quando o valor do ponto é exatamente o mesmo para os dois métodos, o BHCGeo identifica os pixels com diferença de CAD. Um exemplo dessa característica aparece no mês de Janeiro, Figura 7, para o Ano Seco.

O mês de janeiro é um dos meses mais importantes, pois é quando há maior déficit, inclusive muito elevados, na maioria das estações e, portanto, maior fragilidade por parte dos pecuaristas. Este resultado corrobora com trabalhos anteriores realizados por Rocha et al., (2019) que concluíram que a região central do Alto Camaquã possui maior fragilidade frente aos déficits hídricos, com solos de mais baixa resistência, declividade acentuada, solos rasos e pedregosos e maior concentração de pecuaristas e agricultores familiares. 
Figura 7. Déficit e Excedente Hídrico do Alto Camaquã para o mês Janeiro.
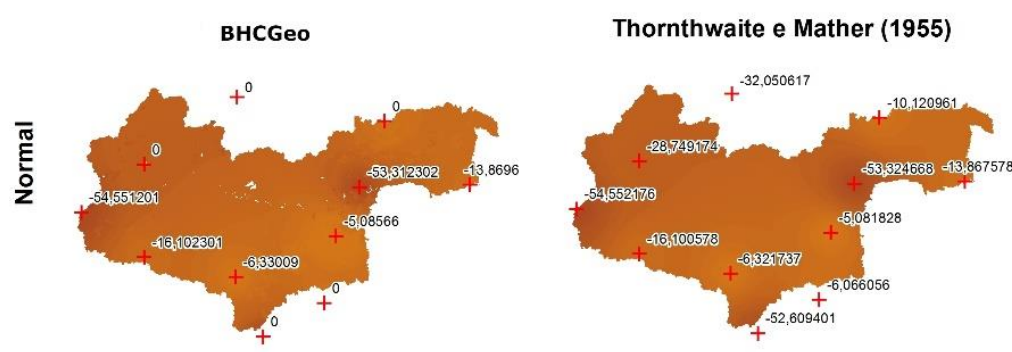

\section{Balanco Hídrico Climatológico - Janeiro -}
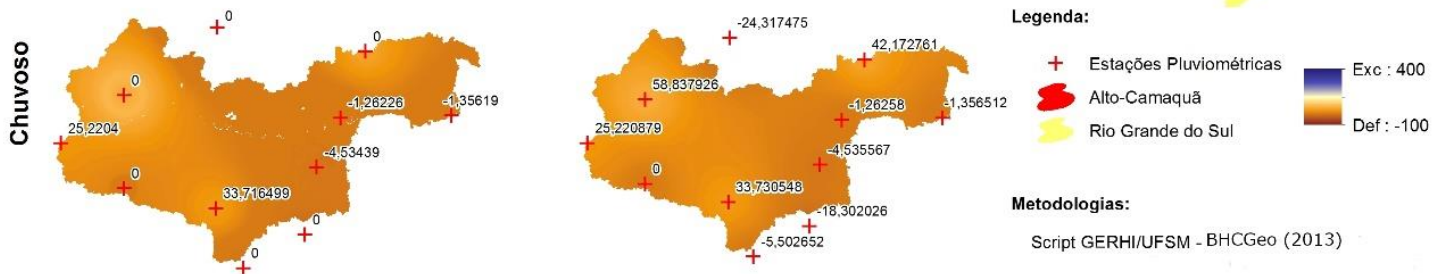

Script GERHI/UFSM - BHCGeo (2013)
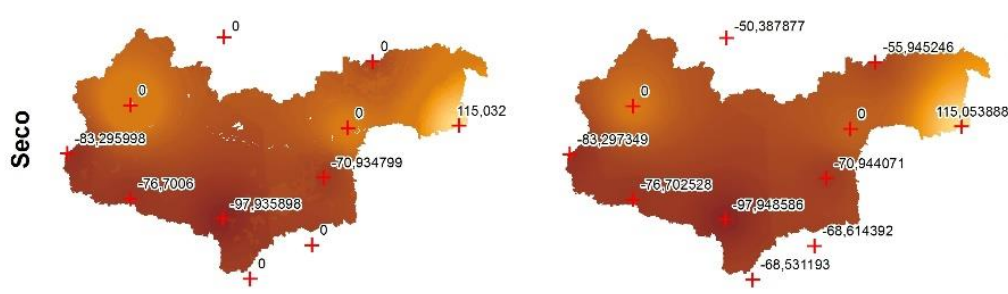

Thorntwaite e Matter (1955) para CAD - 60mm

Fonte:

$$
\begin{aligned}
& \text { Precipitação - ANA (Hidroweb) } \\
& \text { Temperatura - CPTEC e INPE }
\end{aligned}
$$
CAD - Carvalho Neto (2011)

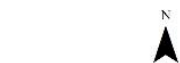

Sistema de Coordenadas: GCS SIRGAS 2000 Datum: SIRGAS 2000

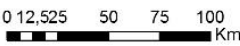

\section{CONCLUSÕES}

Este estudo visou estudar o território do Alto Camaquã a partir de uma perspectiva hídrica, levando em conta duas metodologias que se diferenciam entre si no uso do CAD, a primeira Thorntwaite \& Matter (1955) considera apenas um CAD para toda a BHC, já a segunda (BHCGeo, 2013) por ser feita em ambiente de geoprocessamento considera um CAD para cada uso do solo e tipo de solo.

Os resultados comprovam a hipótese de que os pecuaristas familiares do Alto Camaquã sofrem com muitos meses de déficit hídrico em todo o território. Constatou-se que, independente do cenário, os meses de janeiro e fevereiro são os de maior déficit hídrico em toda a área de estudo. Porém, nos meses de junho à setembro, há excedente hídrico capaz de minimizar os impactos gerados pelo déficit nos meses de verão.

O Alto Camaquã pode ser considerado como produtor de água em todos os anos de estudo, no período do inverno, e esta água é transferida pela sub-bacia do Alto Camaquã e distribuída no Médio e no Baixo Camaquã.

Além disso, pode-se confirmar que o BHC é uma ferramenta muito importante nas análises ambientais, pois, a partir dela, é possível inferir dificuldades e potencialidades do uso dos recursos hídricos.

As metodologias estudadas demonstraram grande eficiência no cálculo do BHC. As diferenças que ocorreram nas duas não modificam o comportamento geral da bacia e portanto, não causam diferenças significativas no que tangem déficit e excesso hídrico. Porém, o segundo método (BHCGeo, 2013) consegue 
diferenciar melhor os locais onde variam os valores de CAD e, para regiões com alta variabilidade de uso de solo e para uma análise mais detalhada, traria resultados mais consistentes.

Entende-se que, independente do método escolhido, as ferramentas de geoprocessamento são muito eficientes na espacialização dos resultados obtidos e para a compreensão do comportamento das bacias hidrográficas.

Espera-se que esses resultados possam servir de auxílio aos tomadores de decisão e que novas políticas públicas sejam trabalhadas para que os déficits hídricos diminuam nos meses de verão. Nesse sentido, é necessário intensificar trabalhos que ajudem essas populações a se adaptarem e aumentarem sua resiliência diante de tais pressões ambientais. Além disso, os excedentes hídricos, nos meses invernais, podem ser utilizados na gestão dos recursos hídricos com o intuito de armazenar água para os períodos mais críticos.

\section{AGRADECIMENTOS}

Os autores agradecem à Coordenação de Aperfeiçoamento de Pessoal de Nível Superior (CAPES), ao Conselho Nacional de Desenvolvimento Científico e Tecnológico (CNPq) e a Fundação de Amparo à Pesquisa do Rio Grande do Sul (FAPERGS) pelo apoio financeiro concedido.

\section{REFERÊNCIAS}

BRASIL, Lei no 9.433 de 8 de janeiro de 1997. Define a Política Nacional de Recursos Hídricos, os princípios e instrumentos da sua gestão, 1997.

Balanço Hídrico Climatizado Geoespacializado em Raster - BHCgeo , 2013, Brasil. Instituição de Registro: INPI - Instituto Nacional da Propriedade Industrial, Número do Registro: BR512018000709-0.

CAMPO, A. M.; ZAPPERI, P. A.; RAMOS, M. B. Recent Rainfall Anomalies in the Southwestern Pampas Region, Argentina. Retrospective And Prospective View. In: II Congreso Interamericano de Cambio Climático, Anais... Ciudad del México: 2016, p. 704-708.CARVALHO NETO, R. M. Uso do Balanço Hídrico Climatológico para subsidiar tomadas de decisão quanto ao manejo de Bacias Hidrográficas. 2011, 90 p. Dissertação (Mestrado em Engenharia Civil) - Universidade Federal de Santa Maria. Santa Maria, 2011.

CARVAlHo Neto, R. M. Análise de incertezas do Balanço Hídrico Climatológico especializado. 2016, 145 p. Tese (Doutorado em Engenharia Florestal) - Universidade Federal de Santa Maria. Santa Maria, 2016.

COLLISCHONN, B. et al. Modelagem Hidrológica de Uma Bacia com Uso Intensivo de Água: Caso do Rio Quaraí-RS. Revista Brasileira de Recursos Hídricos, v. 16, p. 119-133, 2011.

COLLISCHONN, B.; TASSI, R. Introduzindo Hidrologia. Instituto de Previsões Hidrológicas, UFRGS, n. 5, 2008.

FAO. Food and agriculture organization of the United Nations. World food, 2013. Disponível em: https://www.fao.org.br/. Acesso em: 16 jun. /2014.

FEPAM, 2006. Diponível em: http://www.fepam.rs.gov.br/qualidade/bacia camaqua.asp . Acesso em 04 ago.2017

IPCC. Intergovernmental Panel on Climate Change. Climate Change 2001: The Scientific Basis-Contribution of Working Group 1 to the IPCC Third Assessment Report. Cambridge Univ. Press. 2001a.

IPCC. Intergovernmental Panel on Climate Change. Cambios Climáticos 2014: Impactos, Adaptación y vulnerabilidad. Contribución del grupo de trabajo al quinto informe de evaluación del grupo intergubernamental de expertos sobre el cambio climático.34p. 2014.

IPCC. Intergovernmental Panel on Climate Change. Climate Change 2001: Impacts, Adaptation and Vulnerability- Contribution of Working Group 2 to the IPCC Third Assessment Report. Cambridge Univ. Press. 2001b. 
IPCC. Intergovernmental Panel on Climate Change.Climate Change 2007: The Physical Science Basis. Summary for Policymakers. Contribution of Working Group I to the Fourth Assessment Report of the Intergovernmental Panel on Climate Change. Paris, February 2007.

LIMA, J. E. F. W.; FERREIRA, R. S. A.; CHRISTOFIDIS, D. O uso da irrigação no Brasil. In: FREITAS,M. A. V.; ANEEL; OMM; SRH/MMA. (Org.). O Estado das Águas no Brasil - 1999: Perspectivas de gestão e informação de recursos hídricos. 1. ed. p. 73-82, 1999.

MACHADO, C. J. S. Recursos hídricos e cidadania no Brasil: limites, alternativas e desafios. Ambiente \& Sociedade,v. 6, n. 2, p. 121-136, 2003.

NASCIMENTO, N. O.; HELLER, L. Ciência, tecnologia e inovação na interface entre as áreas de recursos hídricos e saneamento. Engenharia Sanitária e Ambiental, Rio de Janeiro, v. 10, n.1, p. 36-48, 2005.

PEREIRA, A R.; ANGELOCCI, L. R.; SENTELHAS, P. C. Meteorologia agrícola. Apostila de curso. ESALQ, 2007. 192p.

REBOUÇAS, A. D. C. Água no Brasil: abundância, desperdício e escassez. Bahia Análise \& Dados,v. 13, n. especial, p. 341-345, 2003.

ROCHA, J. M. ; ROCHA, N. S. ; KAFER, P. S. ; CRUZ, R. C. . Eucalyptus forestry in Brazilian Pampa biome: between developmental illusion and sustainable inefficacy. Ciência e Natura, v. 42, p. e35, 2020.

ROCHA, N.S.; CRUZ, R.C.; PADILHA, D.; CARVALHO, C.M.. Fragilidades ambientais do Alto Camaquã e vulnerabilidade dos pecuaristas familiares frente a disponibilidade hídrica. Raega - O Espaço Geográfico em Análise, v.45, n.1, p.153, 2019.

TAPIA, L. R.; NOVELO, J. A. M. Cambio Climático y Agua en la Cuenca Del Valle De México. In: II Congreso Interamericano de Cambio Climático, Anais... Ciudad del México, 2016. p. 564-465.

THORTHWAITE, C.W.; MATTER, J.R. The water balance. Publications in Climatology, New Jersey, Drexel Institute of Technology, 104p. 1955.

TUCCI, C. E. M. Modelos Hidrológicos. Porto Alegre: UFRGS/ABRH, 1998. 669 p.

TUCCI, C. E. M.Hidrologia: ciência e aplicação. 2.ed. Porto Alegre. Rio Grande do Sul (RS). Editora Universidade. 2000. 943p.

TUCCI, C.E.M.;BELTRAME, L.F. Infiltração e armazenamento no solo: In: Tucci, C.E.M. Hidrologia: ciência e aplicação. 2.ed. Porto Alegre. Rio Grande do Sul (RS). Editora Universidade, p.335-372, 2000.

TUNDISI, J. G. Recursos hídricos no futuro: problemas e soluções. Estudos Avançados, v. 22, 2008. 